\title{
Safety and Efficacy of Methanol Fraction of Moringa oleifera as Antihypertensive in L-NAME Induced Hypertensive Rabbits: Bedside to Bench, Implications for Bench Back to Bedside
}

\author{
A.D.A. Adedapo ${ }^{1, *}$, O.T. Jegede ${ }^{1}$, T.O. Omobowale ${ }^{2}$, W. Nabofa ${ }^{3}$, A.A. Oyagbemi ${ }^{4}$, \\ A.A. Adedapo ${ }^{5}$
}

${ }^{1}$ Department of Pharmacology and Therapeutics; ${ }^{2}$ Department of Veterinary Medicine; ${ }^{3}$ Department of Physiology; ${ }^{4}$ Department of Veterinary Physiology and Biochemistry, and ${ }^{5}$ Department of Veterinary Pharmacology and Toxicology, University of Ibadan, Ibadan, Nigeria

\begin{abstract}
Context: Hypertension, a global menace requires innovative research into the use of Moringa oleifera being promoted and traditionally used as alternative therapy.

Objective: To innovatively evaluate the mechanistic effect, safety and efficacy of the methanol fraction of $M$. oleifera (MMO) leaves on L-NAME induced hypertensive rabbits.

Methods: Rabbits were divided into six groups: Control, L-NAME alone, L-NAME with 100, 200 or $400 \mathrm{mg} / \mathrm{kg}$ of MMO and enalapril. Inclusion and exclusion criteria were similar baseline parameters and Day 3 systolic blood pressure (SBP) less than baseline SBP respectively. The primary outcome was a $10 \%$ reduction of SBP on Day 21. Enalapril group was excluded from analysis. Safety was assessed with liver and renal functions, hydrogen peroxide and nitric oxide concentrations to elucidate mechanistic effect.

Results: Moringa $100 \mathrm{mg} / \mathrm{kg}, 200 \mathrm{mg} / \mathrm{kg}$ and $400 \mathrm{mg} / \mathrm{kg}$ reduced SBP by $4.75,18.00$ and $15.25 \mathrm{mmHg}(\mathrm{F}=22.123$, $\mathrm{p}=0.000$ ). SBP control was achieved with MMO $200 \mathrm{mg} / \mathrm{kg}, 14 \%$ reduction and $400 \mathrm{mg} / \mathrm{kg}, 12 \%$ reduction. Nitric oxide concentration, $0.06,0.094$ and $0.114 \mathrm{mmol}(\mathrm{F}=30.255, \mathrm{p}=0.000)$ dose-dependently increased and was most predictive of SBP control $\left(r^{2}=0.802, p=0.000\right)$. Nitric oxide production was inversely related to heart/body weight ratio which was dose-dependently reduced. MMO reduced hydrogen peroxide and ALT level but no significant effect on urea, HDL, and TG.

Conclusion: MMO reduced SBP and dose-dependently increased nitric oxide concentration in L-NAME induced hypertensive rabbits. The effect may be mediated via activation of nitric oxide pathway. MMO demonstrated a potent anti-oxidant activity and safety. Effect on ventricular hypertrophy needs further evaluation.
\end{abstract}

Keywords: Moringa, hypertension, nitric-oxide, anti-oxidant, intention-to-treat, per protocol.

\section{INTRODUCTION}

Hypertension, a global epidemic is of public health concern, and the prevalence is on the increase [1]. Hypertension or high blood pressure (BP) is a chronic medical condition in which arterial BP is elevated. Therapy includes the use of dietary modifications, antihypertensive medications, and exercise intervention. Herbal remedies and botanicals are employed by individuals for various medical conditions without appropriate disclosure to their physicians [2]. Moringa oleifera (MO) has been advocated as a remedy for hypertension [3]. It is argued that someone suffering from hypertension will benefit from $\mathrm{MO}$ because of its abundant calcium, magnesium, potassium, zinc and vitamins $\mathrm{C}$ and $\mathrm{E}$ [4]. MO has the potential for nutritional security [5] and as a pharmaceutical excipient [6].

*Address correspondence to this author at the Department of Pharmacology and Therapeutics, University of Ibadan; Department of Clinical Pharmacology, University College Hospital, Ibadan, Nigeria; Tel: +2348033635205;

E-mail: debyee1965@yahoo.co.uk, aadedapo@com.ui.edu.ng

E-ISSN: $1929-5634 / 18$
Previous studies on MO have documented the antihypertensive effect and some proposed mechanism(s) of action $[7,8,9]$. However, the safety is yet to be established. This study aims to evaluate the safety and efficacy of methanolic fraction of Moringa oliefera (MMO) as an antihypertensive in L-NAME induced hypertensive rabbits and to elucidate the possible mechanism of action. Phytochemical analysis of methanolic leaf extract of $\mathrm{MO}$ has shown the presence of flavonoids, terpenoids, glycoside, tannins, and saponins [10].

L-NAME inhibits synthesis of nitric oxide, a potent vasorelaxant. Vascular endothelial cells produce nitric oxide (NO) which readily diffuses into the adjacent vascular smooth muscle (VSM) cells resulting in relaxation. This relaxation is achieved through the cGMP second messenger system that leads to activation of calcium pumps embedded in the plasma membrane and sarcoplasmic reticulum. The calcium pumps effectively lower the intracellular calcium concentration causing relaxation of VSM and dilation of the blood vessels [11]. Synthesis of NO is an enantiomer-specific reaction and is inhibited in vitro by 
$\mathrm{N} \omega$-monomethyl-L-arginine (L-NMMA), but not its $\mathrm{D}$ enantiomer [12].

\section{MATERIALS AND METHODS}

\section{Consumable Materials}

Nw-nitro-L-arginine methyl ester (L-NAME) (Sigma Chemical Co. Estonia), AST, ALT, Triglycerides Randox kits, Methyl alcohol, Water, Ethanol, Kit for biochemical tests, Sterile gloves, Needles and syringes, Griess reagents, oxygenated Krebs-HEPES, NADPH oxidase, xanthine oxidase, Nitric oxide synthase and catalase

\section{Non-Consumables}

The tail-cuff computer-aided monitoring device (Automatic Blood Pressure Computer, Model LE 5007, LSI Letica Scientific Instruments, Barcelona Spain), ECG machine, Bucket Centrifuge, Pasteur pipette, Eppendorf tubes, Standing rack.

\section{Methods}

The leaves of MO were collected from the farm, in Ojoo Ibadan, Oyo State Nigeria and identified by Mr. Babalola in the Department of Botany, Faculty of Science, University of Ibadan. The leaf samples were air dried at room temperature and the dried samples were extracted with $100 \%$ methanol. $10 \mathrm{~kg}$ of the dried leaves was used and soaked in 50 litres of $100 \%$ methanol and $198 \mathrm{~g}$ was recovered as the extract. The extracts were collected at least three times and were filtered through Whatman number 1 filter paper and then concentrated on a rotary evaporator (Buchi, Flawil, Switzerland) at $45^{\circ} \mathrm{C}$, dried and kept at $4^{\circ} \mathrm{C}$ till used for the assay. The sample and solvent mass ratio were 1:2 during extraction. The extracts were diluted with sterile water to get the final concentration as per requirement.

\section{Animals}

Adult male rabbits weighing between $1.2 \mathrm{~kg}$ and $1.95 \mathrm{~kg}$ were obtained in a farmhouse at Ojoo, Oyo state. All animals were stabilized and maintained under laboratory conditions (12 h: $12 \mathrm{~h}$ light/ dark cycle, frequent air change) and had free access to tap water and food.

\section{Study Design}

The effect of methanol fraction of MO leaf was examined on blood pressure parameters; mean arterial, systolic and diastolic blood pressure (MABP, SBP, DBP) of rabbits previously treated with L-NAME.

Experimental protocols were carried out in line with the standard ethical guidelines for laboratory animal use and care. Blood pressure and heart rate measurements were determined by the non-invasive method. A stabilization period of 30 minutes was observed before any recording. Heart rate was determined by the use of the Computer-aided electrocardiogram (ECG) monitor.

The study was conducted in University of Ibadan Department of Pharmacology and Therapeutics and Veterinary Medicine. The animals were kept in the animal house while the experiments on the organs and sample extraction were done in the veterinary teaching hospital laboratory.

Rabbits were divided into six groups of four animals each.

Group A: Control rabbits (Distilled water)

Group B: L-NAME induced $(40 \mathrm{mg} / \mathrm{kg}$ ) hypertensive rabbits

Group C: L-NAME induced $(40 \mathrm{mg} / \mathrm{kg}$ ) hypertensive rabbits + Methanol fraction of Moringa oleifera (MMO)treated $(100 \mathrm{mg} / \mathrm{kg}$ body weight)

Group D: L-NAME induced $(40 \mathrm{mg} / \mathrm{kg})$ hypertensive rabbits + MMO-treated ( $200 \mathrm{mg} / \mathrm{kg}$ body weight)

Group E: L-NAME induced $(40 \mathrm{mg} / \mathrm{kg})$ hypertensive rabbits + MMO-treated $(400 \mathrm{mg} / \mathrm{kg}$ body weight) and

Group F: L-NAME induced $(40 \mathrm{mg} / \mathrm{kg}$ ) hypertensive rabbits + Enalapril (40mg/kg body weight).

All drugs were administered daily by gastric intubation on non-anesthetized animals for 3 weeks. The intubation was done daily, on non-anesthetized animals. The dose of the extract was based on previous results $[10,13]$.

Hypertension was ascertained by blood pressure readings measured with tail cuff sphygmomanometer wrapped around the left forearm of the rabbits.

Baseline heart rate, systolic blood pressure (SBP), diastolic blood pressure (DBP) and mean arterial pressure (MAP) were done on day $0,3,7,14$, and at the end of the study on day 21 . Safety was evaluated with liver function (aspartate transaminase, AST and 
alanine transaminase, ALT) and renal function (urea) tests on the aforementioned days.

The hearts were collected, washed in saline and weighed. The samples were homogenized and centrifuged at 3,000 rpm for 15 minutes. Hydrogen peroxide tissue content was evaluated. Nitric oxide tissue content was also evaluated using nitrite measurement at $550 \mathrm{~nm}$ [14]. Total cardiac nitrites concentration was determined according to the method of Granger and colleagues [14]. The heart samples were incubated with enzymatic cofactors and nitrate reductase for $30 \mathrm{~min}$ at room temperature to convert nitrite to nitrate. The reaction was evoked by adding Griess reagent to the solution. The colored substance obtained was determined by spectrophotometer at 540 $\mathrm{nm}$, and its concentration reported as $\mathrm{nmol} / \mathrm{l}$.

\section{Hydrogen Peroxide Production Evaluation}

The heart sample homogenates were incubated in oxygenated Krebs-HEPES (composition in $\mathrm{mmol} \mathrm{L}^{-1}$ :
$\mathrm{NaCl} 118, \mathrm{KCl} 4.5, \mathrm{CaCl}_{2} 2.5, \mathrm{MgCl}_{2}$ 1.2, $\mathrm{KH}_{2} \mathrm{PO}_{4}$ 1.2, $\mathrm{Na}$-HEPES 25, $\mathrm{NaHCO}_{3} 25$ and glucose 5; pH 7.4), at $37^{\circ} \mathrm{C}$. Sixty minutes later, $\mathrm{H}_{2} \mathrm{O}_{2}$ was measured in the incubation medium. These experiments were also performed in the presence of inhibitors of NADPH oxidase (diphenyleneiodonium, DPI, $500 \mu \mathrm{mol} \cdot \mathrm{L}^{-1}$; apocynin $500 \mu \mathrm{mol} \cdot \mathrm{L}^{-1}$ ), xanthine oxidase (oxypurinol, $500 \mu \mathrm{mol} \cdot \mathrm{L}^{-1}$ ), NOS (nitro-L-arginine methyl ester, LNAME, $500 \mu \mathrm{mol} \cdot \mathrm{L}^{-1}$ ) and catalase (aminotriazole, 50 $\left.\mathrm{mmol} \cdot \mathrm{L}^{-1}\right)$.

\section{Serum Transaminases (AST, ALT)}

Randox diagnostic kits were used and the manufacturer protocol followed. The respective parameters were determined by measuring the UV spectrophotometric absorbance.

\section{Statistical Analysis}

Data were analysed using IBM SPSS Statistics version 20 and GraphPad Prism 5. Data are expressed as a mean and standard error of the mean. One way

Table 1: Effect of Methanol Fraction of Moringa oleifera Leaf on Heart Rate (beats/min), Systolic (SBP) and Diastolic Blood Pressure (DBP) and Mean Arterial Pressure (MAP) (mmHg)

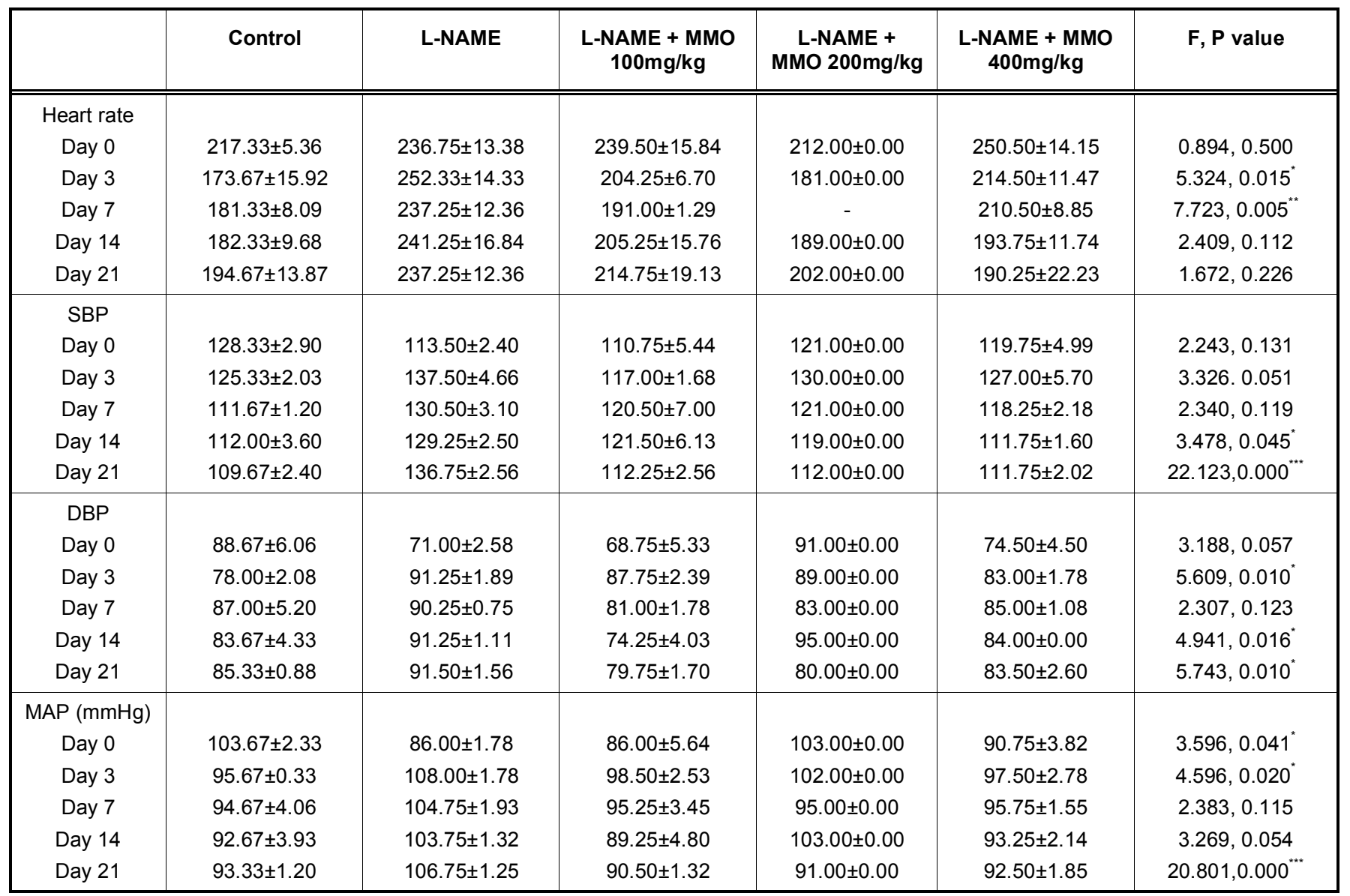

Values $=$ Mean \pm SEM ${ }^{*} p \leq 0.05,{ }^{* *} p \leq 0.01,{ }^{* * *} p \leq 0.001$. 
ANOVA was used for comparison of multiple variables of continuous data, Newman-Keuls multiple comparison tests were carried as post hoc, the level of significance was taken at $p<0.05$.

\section{RESULT}

Moringa $100 \mathrm{mg} / \mathrm{kg}, \quad 200 \mathrm{mg} / \mathrm{kg}$ and $400 \mathrm{mg} / \mathrm{kg}$ respectively reduced blood pressure $(\mathrm{mmHg})$, systolic by $4 \%,(117.0$ to 112.3$) ; 14 \%(130.0$ to 112.0$)$ and $12 \%,(127$ to 111.8$),(F=22.123, p<0.001)$; diastolic by $9 \%,(87.8$ to 79.8$) ; 10 \%,(89.0$ to 80.0$)$ and about $1 \%$ increase, 83 to $83.5(F=5.743, p=0.010)$ between day 3 and day 21 ; and mean arterial pressure by $8 \%,(98.5$ to $90.5) ; 11 \%,(102.0$ to 91.0$)$ and $5 \%,(97.5$ to 92.5$)$ $(\mathrm{F}=20.801, \mathrm{p}<0.001)$. Heart rate, beats/minute reduced by $6 \%,(252.3$ to 237.3$)$ in L-NAME only and L-NAME + MMO $400 \mathrm{mg} / \mathrm{kg} 11 \%$, (214.5 to 190.3) but increased in distilled water control, 173.7 to $194.7,12 \%$; L-NAME + MMO $100 \mathrm{mg} / \mathrm{kg} 204.3$ to 214.8, 5\%;L-NAME + MMO $200 \mathrm{mg} / \mathrm{kg} 187.0$ to $202.0,8 \% \quad(F=1.672, p=0.226)$ Table 1

SBP control was best achieved with MMO $200 \mathrm{mg} / \mathrm{kg}$ and positively correlated with nitrate level.

Effect of Methanol Extract of MMO Leaf on Nitric Oxide Production, Hydrogen Peroxide, and Heart Weight

The groups treated with $\mathrm{MMO}$ had a significant dose-dependent increase of $0.06,0.094$ and $0.144 \mathrm{mmol}$ in nitrite concentration in 100,200 and $400 \mathrm{mg} / \mathrm{kg}$ MMO groups respectively compared with LNAME group $(F=30.255, p<0.001)$ Table 2. Hydrogen peroxide reduced by $20.4 \%, 26.2 \%$ and $8.6 \%$ in $100 \mathrm{mg} / \mathrm{kg}, 200 \mathrm{mg} . \mathrm{kg}$ and $400 \mathrm{mg} . \mathrm{kg}$ MMO treated groups respectively compared to untreated hypertensive control group, Table 2.

There was a dose-dependent reduction in the heart/body ratio of MMO treated groups. However, while the $400 \mathrm{mg} / \mathrm{kg}$ MMO caused a significant reduction, the $100 \mathrm{mg} / \mathrm{kg}$ caused a significant increase compared to normal and untreated hypertensive control $(p<0.05)$. The group treated with $200 \mathrm{mg} / \mathrm{kg} \mathrm{MMO}$ showed an insignificant reduction, Table 2. Nitric oxide production was inversely related to heart/body ratio with a dose-dependent increase of nitric oxide in MMO treated rabbits. Body weight from baseline value increased on day 14 in $200 \mathrm{mg} / \mathrm{kg}$ and $400 \mathrm{mg} / \mathrm{kg}$ MMO treated groups, $p>0.05$, Table 3 .

\section{Safety Profile of MMO on Renal and Liver Function}

All the groups had an increase in urea concentration, though no significant difference between the experimental groups ( $p \geq 0.05$ ), 200 and $400 \mathrm{mg} / \mathrm{kg}$ MMO had more increase, Table 3.

There was an increase in AST level for all experimental groups with 200 and $400 \mathrm{mg} / \mathrm{kg}$ MMO treated group having the highest increase rate of 73 and $74.75 \mu \mathrm{l}$, respectively, Table 3 .

Alanine transferase (ALT) was relatively reduced in the MMO treated groups, Table 3.

SBP control was best achieved with MMO $200 \mathrm{mg} / \mathrm{kg}$ and positively correlated with nitrate level (Table 4). Nitrate was most predictive of SBP control $\left(r^{2}=0.802, p=0.000\right)$ Table 5. Other predictors of SBP control were baseline blood pressure as well as serum levels of albumin and triglyceride on day 7 .

\section{DISCUSSION}

In this experiment, L-NAME induced hypertension model was used and the safety and efficacy of MMO were observed within 21 days. The rabbits showed a reduction in blood pressure and the antihypertensive effect of this extract was not dose-dependent. SBP control was achieved with MMO $200 \mathrm{mg} / \mathrm{kg}, 14 \%$ reduction while $400 \mathrm{mg} / \mathrm{kg}$ exhibited $12 \%$ reduction.

Table 2: Effect of Methanol Extract of Moringa oleifera (MMO) Leaf on Nitric Oxide Concentration, Hydrogen Peroxide Concentration (mmol) and Heart/Body Weight Ratio

\begin{tabular}{|c|c|c|c|}
\hline GROUPS & Nitric oxide & Hydrogen Peroxide & heart/body weight ratio \\
\hline \hline Control(vehicle) & $0.663 \pm 0.033$ & $44.981 \pm 5.24$ & $0.0020 \pm 0.0002$ \\
\hline hypertensive rabbits (L-NAME only) & $0.458 \pm 0.018^{* * *}$ & $58.94 \pm 16.97$ & $0.0023 \pm 0.0005$ \\
\hline hypertensive rabbits + 100mg/kg of MMO & $0.518 \pm 0.011^{* *}$ & $46.91 \pm 5.86$ & $0.0028 \pm 0.0005^{*}$ \\
\hline hypertensive rabbits + 200mg/kg of MMO & $0.552 \pm 0.008^{* * *}$ & $43.471 \pm 1.65$ & $0.0021 \pm 0.0004$ \\
\hline hypertensive rabbits + 400 mg/kg of MMO & $0.602 \pm 0.039^{* * *}$ & $53.89 \pm 13.21$ & $0.0019 \pm 0.0002^{*}$ \\
\hline
\end{tabular}

Values $=$ Mean $\pm S D,{ }^{*} p<0.05,{ }^{* * *} p<0.001$ 
Table 3: Effect of Methanol Fraction of Moringa oleifera Leaf on Transaminases (ALT, AST) $\mu \mathrm{l}$ and Urea (mg/dl) and Body Weight of Rabbits

\begin{tabular}{|c|c|c|c|c|c|c|}
\hline & Control & L-NAME & $\begin{array}{c}\text { L-NAME + MMO } \\
100 \mathrm{mg} / \mathrm{kg}\end{array}$ & $\begin{array}{c}\text { L-NAME + } \\
\text { MMO } 200 \mathrm{mg} / \mathrm{kg}\end{array}$ & $\begin{array}{c}\text { L-NAME + MMO } \\
\text { 400mg/kg }\end{array}$ & F, P value \\
\hline & & & & & & \\
\hline Day 0 & $12.33 \pm 0.33$ & $14.50 \pm 1.76$ & $12.25 \pm 1.60$ & $12.00 \pm 0.00$ & $12.50 \pm 1.04$ & $0.484,0.747$ \\
\hline Day 3 & $44.67 \pm 16.19$ & $32.25 \pm 9.32$ & $30.25 \pm 6.71$ & $29.00 \pm 0.00$ & $38.25 \pm 3.01$ & $0.402,0.804$ \\
\hline Day 7 & $55.50 \pm 17.50$ & $50.50 \pm 9.92$ & $31.75 \pm 4.09$ & $75.00 \pm 0.00$ & $61.50 \pm 4.33$ & $2.861,0.081$ \\
\hline Day 14 & $60.33 \pm 10.14$ & $55.75 \pm 10.07$ & $36.75 \pm 4.99$ & $82.00 \pm 0.00$ & $76.25 \pm 3.79$ & $4.468,0.022^{*}$ \\
\hline Day 21 & $70.33 \pm 9.53$ & $69.00 \pm 9.84$ & $51.25 \pm 7.04$ & $92.00 \pm 0.00$ & $87.25 \pm 2.87$ & $3.522,0.044^{*}$ \\
\hline $\mathrm{ALT} \mu \mathrm{l}$ & & & & & & \\
\hline Day 0 & $93.00 \pm 24.27$ & $97.25 \pm 20.11$ & $96.25 \pm 19.38$ & $162.00 \pm 0.00$ & $131.75 \pm 15.81$ & $1.185,0.370$ \\
\hline Day 3 & $108.67 \pm 24.55$ & $114.25 \pm 12.98$ & $88.75 \pm 21.03$ & $43.00 \pm 0.00$ & $87.00 \pm 24.88$ & $0.771,0.566$ \\
\hline Day 7 & $123.00 \pm 38.00$ & $123.25 \pm 13.03$ & $102.25 \pm 18.75$ & $113.60 \pm 0.00$ & $100.25 \pm 19.28$ & $0.301,0.871$ \\
\hline Day 14 & $126.33 \pm 21.67$ & $130.00 \pm 11.81$ & $107.75 \pm 18.85$ & $120.00 \pm 0.00$ & $100.00 \pm 22.52$ & $0.447,0.772$ \\
\hline Day 21 & $160.33 \pm 17.90$ & $139.00 \pm 10.40$ & $118.50 \pm 17.51$ & $129.00 \pm 0.00$ & $112.50 \pm 21.97$ & $1.047,0.427$ \\
\hline Urea mg/dl & & & & & & \\
\hline Day 0 & $15.67 \pm 0.88$ & $14.50 \pm 0.29$ & $14.50 \pm 0.87$ & $18.00 \pm 0.00$ & $19.25 \pm 0.48$ & $10.158,0.001^{* *}$ \\
\hline Day 3 & $17.00 \pm 1.53$ & $20.00 \pm 0.00$ & $19.50 \pm 1.26$ & $23.00 \pm 0.00$ & $21.00 \pm 1.96$ & $1.392,0.299$ \\
\hline Day 7 & $22.50 \pm 2.50$ & $22.75 \pm 1.31$ & $26.00 \pm 1.73$ & $28.00 \pm 0.00$ & $24.00 \pm 1.47$ & $1.094,0.411$ \\
\hline Day 14 & $23.33 \pm 1.20$ & $25.00 \pm 1.08$ & $26.25 \pm 1.31$ & $30.00 \pm 0.00$ & $26.75 \pm 1.11$ & $2.025,0.160$ \\
\hline Day 21 & $27.33 \pm 0.88$ & $28.50 \pm 1.26$ & $31.75 \pm 2.43$ & $30.00 \pm 0.00$ & $28.50 \pm 0.87$ & $1.091,0.408$ \\
\hline Weight(kg) & & & & & & \\
\hline Day 0 & $1.50 \pm 0.10$ & $1.45 \pm 0.07$ & $1.74 \pm 0.09$ & $1.60 \pm 0.00$ & $1.56 \pm 0.16$ & $0.965,0.464$ \\
\hline Day 3 & $1.52 \pm 0.07$ & $1.43 \pm 0.08$ & $1.71 \pm 0.10$ & $1.65 \pm 0.00$ & $1.53 \pm 0.11$ & $1.353,0.312$ \\
\hline Day 7 & $1.57 \pm 0.07$ & $1.46 \pm 0.10$ & $1.66 \pm 0.09$ & $1.55 \pm 0.00$ & $1.53 \pm 0.10$ & $0.631,0.651$ \\
\hline Day 14 & $1.60 \pm 0.13$ & $1.50 \pm 0.10$ & $1.66 \pm 0.12$ & $1.70 \pm 0.00$ & $1.54 \pm 0.09$ & $0.444,0.775$ \\
\hline Day 21 & $1.65 \pm 0.15$ & $1.51 \pm 0.08$ & $1.61 \pm 0.14$ & $1.70 \pm 0.00$ & $1.59 \pm 0.07$ & $0.273,0.889$ \\
\hline
\end{tabular}

"P $<0.05, " p \leq 0.001$

Table 4: Correlation Showing Relationship between Nitric Oxide Production and Heart Weight with other Variables in Moringa oleifera Methanol Fraction Treated L-NAME Induced Hypertensive Rabbits

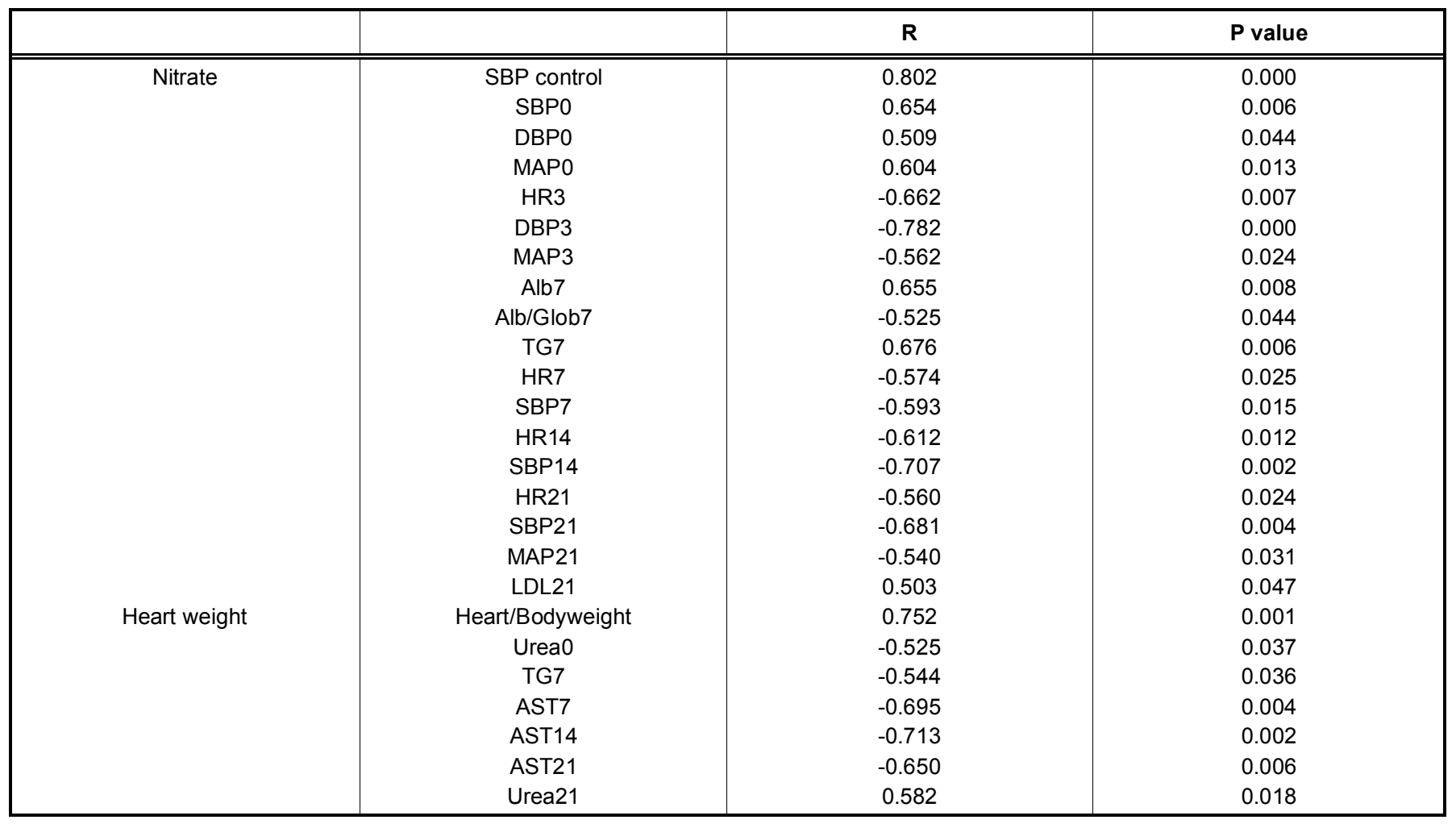


Table 5: Predictors of Systolic Blood Pressure Control in Moringa oleifera Methanol Fraction Treated L-NAME Induced Hypertensive Rabbits

\begin{tabular}{|c|c|c|}
\hline & Standardized Coefficient & P-value \\
\hline Nitrate & 0.802 & 0.000 \\
\hline Weight Day 0 & 0.317 & 0.120 \\
\hline SBP0 & 0.708 & 0.002 \\
\hline MAPO & 0.663 & 0.005 \\
\hline HR3 & -0.631 & 0.005 \\
\hline DBP3 & -0.498 & 0.050 \\
\hline HR14 & 0.569 & 0.022 \\
\hline TG3 & 0.504 & 0.046 \\
\hline Alb7 & 0.826 & 0.000 \\
\hline TG7 & 0.667 & 0.007 \\
\hline TG14 & 0.589 & 0.016 \\
\hline AST Day 14 & 0.509 & 0.044 \\
\hline
\end{tabular}

This may suggest that MMO $200 \mathrm{mg} / \mathrm{kg}$ is more potent. Drugs usually bind to receptors to elicit their response, as dose increases, the response may increase, but the increment may diminish with increasing dose due to receptor saturation. Prolonged exposure in terms of dose or duration may also result in internalization and downregulation of receptors [15].

However, there is a suggestion of a paradoxical effect of blood pressure lowering effect and presumably ventricular hypertrophy based on the increasing heart to body weight with reducing blood pressure. It has been argued that L-NAME model of hypertension may have an unexpected effect on ventricular hypertrophy. There was a significant reduction in heart rate of $\mathrm{MMO}$ treated groups when compared to the L-NAME treated group. Increase nitric oxide production for rabbits treated with MMO compared with L-NAME treated group suggests that $\mathrm{MMO}$ activates nitric oxide pathway as one of the mechanisms by which it exerts it's the anti-hypertensive effect. The leaves of MMO contain nitrile glycosides which are reported to have hypotensive and antioxidant activities [8, 9, 16]. Though muscarinic receptor activation was excluded in the previous study with fractions of ethanol extract of Moringa oleifera [8], the diuretic effect may be involved
$[4,17,18]$. L-arginine esters are competitive muscarinic antagonists [17].

MMO has no significant effect on hydrogen peroxide concentration although it reduced its concentration when compared with L-NAME treated group. Plasma peroxide has been found to be higher in hypertensive patients compared normotensive subjects [19]. The reduction of hydrogen peroxide exhibited by MMO will be beneficial in a hypertensive patient and may be of therapeutic value. Oxygen free radicals, including hydrogen peroxide, may mediate oxidative stress in target organ tissues and contribute to cardiovascular complications in hypertension.

Also, reduction of hydrogen peroxide concentration, though not significant, indicates a potent antioxidant activity. This may explain some of its immune boosting related use. Vascular oxidative stress has been ameliorated with Moringa seeds in spontaneously hypertensive rats [20]. MMO reduced ALT level but no significant effect on urea, HDL, and TG.

Moringa had no significant effect on body weight compared to the control groups but reduced heart weight at a high concentration of $400 \mathrm{mg} / \mathrm{kg}$. Rabbits in the enalapril group died by day 21 ; the question is, is 
enalapril poorly tolerated in rabbits or is Moringa oleifera more tolerable and safer than enalapril? Further studies are needed for this.

We innovatively adapted clinical research concept of "intention-to-treat" of randomized clinical trials to preclinical research. However, "per protocol" which focus on the subset of intention-to-treat which completed the study to day 21 was analysed [21]. This study has implications for dose recommendation of Moringa oleifera in humans as it suggests no beneficial effect of the $400 \mathrm{mg} / \mathrm{kg}$ over the $200 \mathrm{mg} / \mathrm{kg}$. Previous acute toxicity study showed no deaths in experimental animals administered $200 \mathrm{mg} / \mathrm{kg}, \quad 400 \mathrm{mg} / \mathrm{kg}$ and $800 \mathrm{mg} / \mathrm{kg}$ of methanolic leaf extract of commercially processed Moringa oleifera but increasing severity of lethargy and mortality were recorded with doses of $1600 \mathrm{mg} / \mathrm{kg}$ and $3200 \mathrm{mg} / \mathrm{kg}$ [10]. It is therefore suggested that the maximum dose in humans must not exceed $200 \mathrm{mg} / \mathrm{kg}$.

\section{CONCLUSION}

Methanol fraction of MMO leaf reduced the blood pressure, heart rate and cardiac hypertrophy in LNAME treated rabbits. Our results showed that nitric oxide pathway activation might be one of the mechanisms of action for its antihypertensive effects.

Also, the reduction of hydrogen peroxide concentration indicated a potent antioxidant activity. It showed strong reducing power and free radical scavenging capacity. The methanol extract of the leaf was well tolerated by experimental animals and showed no toxicity. A reduced level of ALT and no effect on urea concentration may be suggestive of the safety.

\section{ACKNOWLEDGEMENTS}

We appreciate Mrs. Oluwasoga of IITA for her contribution towards the data analysis. Professor Sola Ogunniyi's kind prompt review of the manuscript is appreciated.

\section{DECLARATION OF CONFLICTING INTERESTS}

The authors declared no conflicts of interest.

\section{FUNDING}

The authors received no financial support for the research.

\section{REFERENCES}

[1] World Health Report: Reducing risks, promoting healthy life Geneva, Switzerland: World Health Organization, 2002. http: //www.who.int/whr/2002.

[2] Adedapo A, Adeagbo AS, Adedapo AA. Use of botanical therapies among patients in secondary health facilities in south west Nigeria: Implications for medical education RPMP 2013; 35: 299-310.

[3] Jed WF. Moringa oleifera: A review of the medical evidence for its nutritional, therapeutic and prophylactic properties. Trees of Life Journal 2005; 1(1): 5.

[4] Anwar F, Latif S, Ashraf M, Gilani AH. "Moringa oleifera: a food plant with multiple medicinal uses. Phytotherapy Research 2007; 21(1): 17-25. https://doi.org/10.1002/ptr.2023

[5] James A, Zinkankuba V. Moringa oleifera a potential tree for nutritional security in sub-Saharan Africa. Am J Res Comm 2017: 5(4). www.usa-journals.com. [Accessed on 2018 July 13].

[6] Uphadek B, Shinkar DM, Patil PB, Saudagar RB. Moringa oleifera as a pharmaceutical excipient. Int $\mathrm{J}$ Curr Pharm Res 2018; 10(2): 13-16.

https://doi.org/10.22159/ijcpr.2018v10i2.25883

[7] Dangi SY, Jolly Cl, Narayanan S. Antihypertensive activity of total alkaloids from the leaves of Moringaoleifera. Pharm Bio 2002; 40(02): 144-148.

https://doi.org/10.1076/phbi.40.2.144.5847

[8] Gilani AH, Aftab K, Suria A, et al. Pharmacological studies on hypotensive and spasmolytic activities of pure compounds from Moringa oleifera. Phytotherapy Research 1994; 8(2): 87-91.

https://doi.org/10.1002/ptr.2650080207

[9] Faizi S, Siddiqui BS, Saleem R, Siddiqui S, Aftab K, Gilani $\mathrm{AH}$. Fully acetylatedcarbamate and hypotensive thiocarbamate glycosides from Moringa oleifera. Phytochemistry 1995; 38(4): 957-963.

https://doi.org/10.1016/0031-9422(94)00729-D

[10] Adedapo AA, Falayi OO, Oyagbemi AA. Evaluation of the analgesic, anti-inflammatory, antioxidant, phytochemical and toxicological properties of the methanol leaf extract of commercially processed Moringa oleifera in some laboratory animals. J Basic Clin Physiol Pharmacol 2015; 26: 491-499.

[11] Shepherd JT, Katusic ZS. Endothelium-derived vasoactive factors: I. Endothelium-dependent relaxation. Hypertension 1991; 18: 76-85.

https://doi.org/10.1161/01.HYP.18.5 Suppl.III76

[12] Palmer RMJ, Ashton DS, Moncada S. Vascular endothelial cells synthesize nitric oxide from L-arginine. Nature 1988; 333: 664-66. https://doi.org/10.1038/333664a0

[13] Jaiswal D, Rai PK, Kumar A, Mehta S, Watal G. Effect of Moringa oleifera Lam. Leaves aqueous extract therapy on hypoglycemic rats. J Ethnopharm 2009; 123(3): 392-396. https://doi.org/10.1016/j.jep.2009.03.036

[14] Granger DL, Anstey NM, Miller WC, Weinberg JB. Measuring nitric oxide production in human clinical studies. Methods Enzymol 1999; 301: 49-61. https://doi.org/10.1016/S0076-6879(99)01068-X

[15] von Zastrow M. Drug receptor and pharmacodynamics. In: Katzung BG, editor. Basic and clinical pharmacology. $14^{\text {th }}$ ed. USA: McGraw-Hill 2018; p. 20-40.

[16] Gupta R, Dubey DK, Kannan GM, Flora SJS. Concomitant administration of Moringa oleifera seed powder in the remediation of arsenic-induced oxidative stress in mouse. Cell Biol Int 2007; 31(1): 44-56. https://doi.org/10.1016/j.cellbi.2006.09.007 
[17] Buxton ILO, Cheek DJ, Eckman D, Westfall DP, Sanders $\mathrm{KM}$, Keef KD., NG-nitro L-arginine methyl ester and other alkyl esters of arginine are muscarinic receptor antagonists. Circ Res 1993; 72: 387-95.

https://doi.org/10.1161/01.RES.72.2.387

[18] Carceres A, Saraiva A, Rizzio S, Zabala L, De Leon E, Navy F. Pharmacological properties of Moringa oleifera. 2: screening for antispasmodic, anti-inflammatory and diuretic activity. J Ethnopharmacol 1992; 36(3): 233-237. https://doi.org/10.1016/0378-8741(92)90049-W

[19] Lacy F, O'Connor DT, Schmid-Schonbein GW. Plasma hydrogen peroxide production in hypertensives and normotensive subjects at genetic risk of hypertension. J Hypertens 1998; 16(3): 291-303.

https://doi.org/10.1097/00004872-199816030-00006

[20] Randriamboavonjy JI, Rio M, Pacaud P, Loirand G, Tesse A Moringa oleifera seeds attenuate vascular oxidative and nitrosactive stresses in spontaneously hypertensive rats. Oxid Med Cell Longev 2017; 4129459.

[21] Gupta SK. Intention-to-treat concept: A review. Perspective Clin Res 2011; 2(3): 109-112.

https://doi.org/10.4103/2229-3485.83221 